\title{
PSC-MSC-Derived Exosomes Protect against Kidney Fibrosis In Vivo and In Vitro through the SIRT6/ $\beta$-Catenin Signaling Pathway
}

\author{
Limin Liu ${ }^{1, *}$, Yao $\mathrm{Wu}^{1, *}$, Pingan Wang ${ }^{1}, \mathrm{Min} \mathrm{Shi}^{1}$, Juning Wang ${ }^{1}$, Huaifen $\mathrm{Ma}^{1}$, Dangze Sun ${ }^{2}$

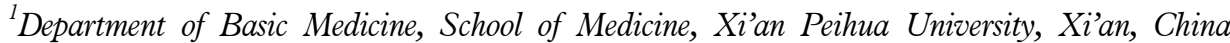 \\ ${ }^{2}$ Department of Thoracic Surgery, Xi'an Chest Hospital, Xi'an, China
}

\begin{abstract}
Background and Objectives: Chronic kidney disease (CKD) has a major impact on the quality of life of patients, and renal fibrosis is a critical pathological change in the disease. It is very important to control the process of renal fibrosis to improve the quality of life of patients with CKD. The pathological mechanism of renal fibrosis is very complicated, and the current treatment strategy also has many flaws.

Methods and Results: To explore a better treatment, we collected exosomes from pluripotent stem cell (PSC)-derived mesenchymal stem cells (MSC) and verified their therapeutic effect on renal fibrosis through in vivo and in vitro experiments. In this study, we found that PSC-MSC-derived comes could prevent the epithelial differentiation of NRK-52E cells, and with increasing exosome concentrations, the effect was improved. Furthermore, PSC-MSC-derived exosomes could reduce the pathological process of renal fibrosis, reduce inflammatory reactions and improve renal function in UUO mice. Moreover, the protective effect of exosomes against renal fibrosis may be achieved by increasing the expression of SIRT6 and decreasing the expression of $\beta$-catenin and its downstream products.

Conclusions: These findings suggest the possibility of PSC-MSC-derived exosomes as a new, effective therapeutic tool for kidney fibrosis.
\end{abstract}

Keywords: Exosomes, Renal fibrosis, UUO, SIRT6

\section{Introduction}

Renal fibrosis $(\mathrm{RF})$ is a common condition and the

Received: November 8, 2020, Revised: May 5, 2021,

Accepted: May 6, 2021, Published online: June 30, 2021

Correspondence to Dangze Sun

Department of Thoracic Surgery, Xi'an Chest Hospital, 127\#

Chang'an South Road, Xi'an 710100, China

Tel: +86-029-62500116, Fax: +86-029-62500116

E-mail: sundangze@163.com

${ }^{*}$ These authors contributed equally to this work.

(c) This is an open-access article distributed under the terms of the Creative Commons Attribution Non-Commercial License (http://creativecommons.org/ licenses/by-nc/4.0/), which permits unrestricted non-commercial use, distribution, and reproduction in any medium, provided the original work is properly cited.

Copyright (c) 2021 by the Korean Society for Stem Cell Research main pathological basis of many chronic kidney diseases, which lead to end-stage renal disease $(1,2)$. Chronic kidney disease seriously affects the patient quality of life and threatens health (3). Therefore, preventing the progression of renal fibrosis is essential for CKD patients. During renal fibrosis, the sustained injury of endothelial cells and epithelial cells (4), the recruitment of inflammatory cells (5) and the activation of myofibroblasts (6) play important roles. At present, the prevention of renal fibrosis mainly targets the abovementioned mechanism. Although there are various treatment options for renal fibrosis, none of them can achieve satisfactory results (7). A new comprehensive and effective treatment strategy is urgently needed clinically.

Mesenchymal stem cells (MSCs) are a heterogeneous subset of stromal stem cells with multiple surface markers 
(CD13, CD29, CD90, CD71 and CD105, etc.) that can be isolated from many adult tissues. They can differentiate into cells of the mesodermal lineage, such as adipocytes, osteocytes and chondrocytes, as well as cells of other embryonic lineages (8). It has been proved that MSCs can effectively promote tissue regeneration and repair (9-11), and MSCs have also been widely used in the treatment of kidney diseases (12). Studies have shown that exosomes derived from MSCs play important roles in protecting the kidney (13). However, excessive in vitro passage of MSCs leads to cell differentiation, which will seriously affect the composition of MSC-derived exosomes. Tissue repair requires large amounts of exosomes, which places high demands on the number of MSCs, requiring staff to continuously extract MSCs, which undoubtedly increases the workload. Pluripotent stem cell (PSC)-derived mesenchymal stem cells (PSC-MSCs) have been shown to have the characteristics of both MSCs and PSCs (14). However, the function of PSC-MSC remains controversial. For example, some scholars have used PSC-MSC-derived exosomes to treat bone defects (15). While Sfougataki et al. (16) claimed that PSC-MSCs were inefficient in their ability to form hyaline cartilage, which confirmed its limitation. Although multiple studies focused on the MSC-derived exosomes, the effect of PSC-MSC-derived exosomes on the reversal of renal fibrosis and the related mechanisms are still unclear.

Sirtuin 6 (SIRT6) is a conserved nicotinamide adenine dinucleotide-dependent protein deacetylase that has also been suggested to effectively reverse the fibrosis process in many organs, such as myocardial fibers. In kidney disease, Muraoka et al. (17) found that the Nampt-SIRT6 axis plays an active and protective role in the deposition of extracellular matrix in diabetic nephropathy. Liu et al. (18) demonstrated that SIRT6 was downregulated in diabetic nephropathy and adriamycin-induced nephropathy models. Cai et al. (19) found that SIRT6 could block the expression of $\beta$-catenin target genes to protect against renal fibrosis.

Exosomes (characterized by surfaced marker CD63, CD73, etc.) are a subset of EVs with an average diameter of 100 nanometers, which are synthesized from endosomes. Through the interactions with other intracellular vesicles and organelles, the final content of the exosomes was determined. The constituents include nucleic acids, proteins, lipids, amino acids, and metabolites. Recently, it has been reported that exosomes play key roles in intercellular communication (20). In the present study, we investigated the antagonistic effects of different concentrations of PSC-MSC-derived exosomes on renal fibrosis. At the same time, we suggested that PSC-MSC-derived exosomes exert protective effects on the kidney through the SIRT6/ $\beta$ catenin signaling pathway.

\section{Materials and Methods}

\section{Generation of PSC-MSC-Exosomes}

Human-induced PSC-MSCs were purchased from the Fourth Military Medical University and cultured in MGro- 500 chemically defined serum-free MSC medium (StemRD, Burlingame, USA). The cells of $3 \sim 8$ passages were applied in this study. After being cultured for 3 days, the culture medium of PSC-MSCs was collected and centrifuged at $300 \times \mathrm{g}$ for 10 minutes and at $2,000 \times \mathrm{g}$ for 10 minutes to remove dead cells and cellular debris. Then, the supernatant was filtered through a $0.22-\mu \mathrm{m}$ filter sterilizer (Steritop ${ }^{\mathrm{TM}}$; Millipore, Billerica, USA) to remove the residual cellular debris. Subsequently, the supernatant was centrifuged at $4,000 \times \mathrm{g}$ and reduced to approximately $200 \mu \mathrm{l}$ by ultrafiltration in a $15 \mathrm{ml}$ Amicon Ultra-15 centrifugal filter unit (Millipore, Billerica, USA). The ultrafiltrated liquid was washed twice with $15 \mathrm{ml}$ of phosphate-buffered saline (PBS) and ultrafiltrated again at $4,000 \times \mathrm{g}$ to $200 \mu \mathrm{l}$. For exosome purification, the liquid was overlaid on a $30 \%$ sucrose-D2O cushion in a sterile Ultra-Clear ${ }^{\mathrm{TM}}$ tube (Beckman Coulter, Kraemer Boulevard Brea, USA) and ultracentrifuged at $100,000 \times \mathrm{g}$ for 2 hours to pellet the small vesicles corresponding to exosomes. The pelleted exosomes were resuspended in $15 \mathrm{ml}$ of PBS and centrifuged at $4,000 \times \mathrm{g}$ in centrifugal filter units until the final volume was reduced to approximately $200 \mu \mathrm{l}$. All procedures were performed at $4^{\circ} \mathrm{C}$. The cell characterization was performed through FACS to determine the expression of CD90, CD45, CD105 and CD19 (all antibodies above were purchased from Abcam, Cambridge, UK). The characterization for exosomes was performed by TEM (transmission electron microscope), Western blot and NTA (Nanoparticle tracking analysis, NanoSight LM10 system, Malvern instruments) according to Théry's guideline (21). In this study, medium after culturing for 3 days as Control in Western blot.

\section{Cell culture and experimental groups}

The NRK-52E renal tubular epithelial cell line ATCC $^{\circledR}$ CRL-1730 ${ }^{\mathrm{TM}}$ ) was cultured in Dulbecco's modified Eagle's medium (DMEM, HyClone, USA) supplemented with 5\% fetal bovine serum (FBS, BioCytoSci, TX, USA) and $1 \%$ antibiotics at $37^{\circ} \mathrm{C}$ in a humidified $5 \% \mathrm{CO}_{2}$ incubator. Cells were seeded on 6-well plates (Corning, NY, USA) at a density of $1 \times 10^{5}$ cells $/ \mathrm{ml}$ and incubated with the follow- 
ing factors: (1) pure DMEM (Con); (2) medium containing TGF- $\beta 1$ (5 ng/ml for $48 \mathrm{~h}$, TGF- $\beta 1)$; (3) medium containing TGF- $\beta 1$ and exosomes $\left(10^{6}\right.$ particles $/ \mathrm{ml}$, Exos-L); (4) medium containing TGF- $\beta 1$ and exosomes $\left(10^{7}\right.$ particles $/ \mathrm{ml}$, Exos- $\left.\mathrm{M}\right)$; and (5) medium containing TGF- $\beta 1$ and exosomes ( $10^{8}$ particles/ml, Exos-H).

\section{Quantitative real-time PCR}

NRK-52E cells were cultured under different conditions and collected to evaluate the transcriptional level of related genes on day 2. Briefly, total RNA was extracted according to the instructions for the RNA extraction kit (TRIzol reagent, Invitrogen Life Technologies). The obtained RNA was then used to prepare cDNA by reverse transcription using PrimeScript RT master mix (TaKaRa, Tokyo, Japan), and a Bio-Rad CFX96 PCR manager system (Bio-Rad, Hercules, CA) was used to perform real-time PCR. The primers used in this study are listed in Table 1, and GAPDH was used as a housekeeping gene. The relative gene expression was normalized to that of the housekeeping gene GAPDH through the $\Delta \Delta \mathrm{Ct}$ method.

\section{Western blotting}

Total protein samples were prepared from kidney tissue and cultured NRK-52E cells using Cell Lytic M (SigmaAldrich, St. Louis, MO) according to the instructions. The specimens were stored at $-80^{\circ} \mathrm{C}$. The primary antibodies used in the study were as follows: anti-E-cadherin (Abcam, Cambridge, UK), anti-Coll-Al (Abcam, Cambridge, UK), anti- $\alpha$-SMA (Abcam, Cambridge, UK), anti-SIRT6 (Abcam, Cambridge, UK) and anti- $\beta$-catenin (Abcam, Cambridge, UK). $\beta$-actin (Sigma-Aldrich) was used to control for protein loading.

Table 1. List of genes and primer sequences

\begin{tabular}{cll}
\hline Gene & Primer & \multicolumn{1}{c}{ Primer $\left(5^{\prime}-3^{\prime}\right)$} \\
\hline Col1-A1 & Forward & GAGTGAGGCCACGCATGA \\
& Reverse & AGCCGGAGGTCCACAAAG \\
$\alpha$-SMA & Forward & CCCCTGAAGAGCATCGGACA \\
& Reverse & TGGCGGGGACATTGAAGGT \\
Fibro & Forward & TACCAGAGGGGAAAAACGCC \\
& Reverse & GCAGCGGTACAGATCCGAATC \\
PAl-1 & Forward & CACAGGCACTGCAAAAGGTC \\
& Reverse & TGTGCCGAACCACAAAGAGA \\
Fsp1 & Forward & AGCTACTGACCAGGGAGCTG \\
& Reverse & CATTGTCCCTGTTGCTGTC \\
Axin2 & Forward & CGACGCACTGACCGACGATT \\
& Reverse & CGAAGGCAGCAGGTTCCACAG \\
GAPDH & Forward & CTGATGCCTCCATGTTGTG \\
& Reverse & GGATGCAGGGATGATGTTCT \\
\hline
\end{tabular}

\section{Animals and surgical protocol}

The animal protocols were approved by the Animal Research Committee of the Xi'an Peihua University (No. IACUC-20190402). Thirty male C57BL/6 mice applied from the Fourth Military Medical University were used for this study and were randomly divided into 4 groups. (1) Mice without any treatment were used as the Con group. (2) After anesthesia, the left abdomen was opened to view the kidney, and the ureter was located inside the lower pole of the left kidney. A 4-0 suture was used to ligate the upper pole of the free ureter near the calyces, and then the ureter was removed (UUO group). (3) After anesthesia, the left abdomen was opened to view the kidney, and then the abdominal cavity was closed (Sham group). (4) PSC-MSC-Exosomes with particles amounts of about $1 \times 10^{11}$ were injected into UUO mice via the tail vein (Exo-H group).

\section{Creatinine and blood urea nitrogen}

Blood was collected from the hearts of mice in each group. The blood samples were coagulated for 2 hours at room temperature (RT) and centrifuged for 20 minutes at $2,000 \times \mathrm{g}$. The plasma was collected, and blood urea nitrogen (BUN) and serum creatinine were analyzed. The BUN level in plasma was measured using a BUN-E kit (Asan Pharm, Seoul, Korea), and the serum creatinine level was measured using a QuantiChrom creatinine assay kit (Bioassay Systems, Hayward, CA). Sample analysis was performed according to the manufacturer's recommended protocols.

\section{Immunofluorescence staining}

NRK-52E cells were seeded on glass coverslips, washed with PBS and fixed in cold methanol : acetone $(1: 1)$ for 10 minutes at $-20^{\circ} \mathrm{C}$. After being washed with phosphatebuffered saline, the fixed cells were blocked in $10 \%$ normal goat serum for 30 minutes. Then, the cells were incubated with primary antibodies (SIRT6, Abcam, Cambridge, UK) overnight, followed by incubation with goat anti-rabbit IgG conjugated with Alexa Fluor 594 or 488 (Abcam, Cambridge, UK) for 1 hour at $37^{\circ} \mathrm{C}$. The cells were also stained with 4,6-diamidino-2-phenylindole to visualize the nuclei. Eventually, the slides were examined under a ZEISS LSM780 confocal microscope (Oberkochen, Germany).

\section{Histology and immunohistochemical (IHC) staining}

The kidney tissues were fixed in $10 \%$ formalin at RT. The paraffin-embedded sections were deparaffinized with xylene and dehydrated in gradually decreasing concentrations of ethanol. For immunohistochemical analysis, 
the dehydrated tissue sections were immersed in $10 \mathrm{mM}$ sodium citrate buffer $(\mathrm{pH} 6.0)$ for 5 minutes at $95^{\circ} \mathrm{C}$. The last step was repeated using fresh $10 \mathrm{mM}$ sodium citrate solution. The sections were incubated in the same solution while cooling for 20 minutes, and they were then rinsed in phosphate-buffered saline PBS. Next, the sections were incubated with a primary antibody (fibronectin, Abcam, $1: 100$ dilution) for 1 hour at $37^{\circ} \mathrm{C}$. After three serial washes with PBS, the sections were processed by an indirect immunoperoxidase technique using a commercial EnVision System kit (DAKO, Carpinteria, CA, USA). Immunohistochemical images were viewed with an Eclipse 80i microscope (Nikon, Tokyo, Japan).

\section{Enzyme-linked immunosorbent assay (ELISA)}

Blood was collected from the mice, and the serum was separated. The concentrations of interleukin (IL)- 6 and TNF- $\alpha$ in mouse serum were quantified using enzymelinked immunosorbent assay (ELISA) kits (R\&D Systems, Hangzhou, China) according to the manufacturer's instructions. The absorbance at $450 \mathrm{~nm}$ was measured using an ELISA reader (BMG Labtech, Ortenaukreis, Germany).

\section{Statistical analysis}

All data are presented as the means \pm SEM and were subjected to one-way analysis of variance (ANOVA) with Tukey's multiple comparison tests. Statistical significance was examined using GraphPad Prism 5 (GraphPad Software, Inc., San Diego, CA, USA). A value of $\mathrm{p}<0.05$ indicated a significant difference.

\section{Results}

\section{Purification, isolation, and characterization of exosomes and PSC-MSCs}

The results of characterization for PSC-MSCs were listed in Supplementary Fig. S1 while results of PSC-MSCExosomes characterization were listed in Supplementary Fig. S2. The results showed that the expression of CD90 and $\mathrm{CD} 105$ was $99.3 \%$ and $99.8 \%$ respectively, which confirmed that the cells meet the standards of MSCs. PSCMSCs retained the proliferative ability for at least 40 days (Supplementary Fig. S1). Furthermore, results of nanoparticle tracking analysis (NTA) and transmission electron microscopy (TEM) revealed that the exosomes obtained from PSC-MSCs mainly occupied a diameter of 10 150 $\mathrm{nm}$ and presented the typical morphological features of exosomes. Results of western blot showed that all exosome specimens were positive for exosome markers (CD63 and CD73), negative for the cellular marker GM130.

\section{Antifibrotic effect of PSC-MSC-Exosomes on TGF- $\beta$ 1-treated NRK-52E cells}

To confirm the preventive effect of PSC-MSC-Exosomes on epithelial dedifferentiation processes, we investigated the protein and gene expression of TGF- $\beta 1$-treated NRK-52E cells. In this study, the protein expression of Coll-A1 and $\alpha$-SMA was increased, and E-cadherin was decreased by TGF- $\beta 1$ administration (Fig. 1A). In addition, after the administration of PSC-MSC-Exosomes, we found that Coll-Al and $\alpha$-SMA expression was decreased and E-cadherin was increased compared with those of the TGF- $\beta 1$ group. Moreover, with increasing exosome con-

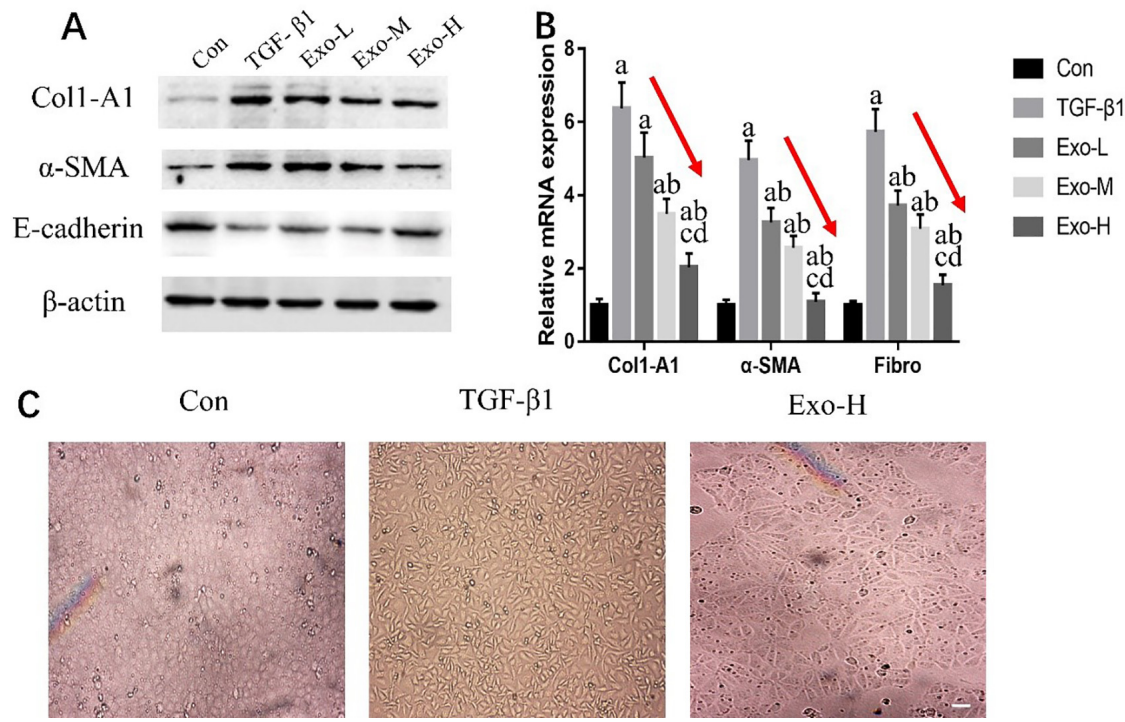

Fig. 1. PSC-MSCs-Exosomes inhibit the occurrence of epithelial differentiation in TGF- $\beta$ 1-treated NRK-52E cells. (A) Western blot analysis of Col1-A1, $\alpha$-SMA and E-cadherin protein expression in NRK-52E cells under different conditions. (B) Real-time PCR analysis of Col1-A1, $\alpha$-SMA and Fibro gene expression in NRK-52E cells under different conditions. (C) Representative morphology of cells in the different groups. Bar $=100 \mu$ m. $\mathrm{n}=3$ in each group, ${ }^{\mathrm{a}} \mathrm{p}<0.05$ vs. the Con group, ${ }^{b} p<0.05$ vs. the TGF- $\beta 1$ group, ${ }^{c} p<0.05$ vs. the Exo-L group, ${ }^{\mathrm{d}} \mathrm{p}<0.05$ vs. the Exo-M group. 
centrations, Coll-Al and $\alpha$-SMA expression showed a decreasing trend, while E-cadherin showed an increasing trend (Fig. 1A). Subsequently, real-time PCR showed that profibrotic genes, including Coll-A1, $\alpha$-SMA and Fibro, were significantly increased in the TGF- $\beta 1$ group and decreased in the Exo groups $(\mathrm{p}<0.05)$, and there was a decreasing trend from the Exo-L to Exo-H group $(\mathrm{p}<0.05)$ (Fig. 1B). As shown in Fig. 1C, in the absence of TGF- $\beta 1$ exposure, NRK-52E cells presented a typical epithelial morphology and formed a cobblestone monolayer. After treatment with TGF- $\beta 1$ for 24 hours, NRK-52E cells exhibited fibroblast-like shuttle-type morphology. We also used Exo-H-treated TGF- $\beta$ 1-treated NRK-52E cells and found that the morphology of the cells was between the cobblestone monolayer and shuttle type.

\section{PSC-MSC-Exosomes attenuated fibrotic processes in UUO mice}

We used IHC staining to examine fibronectin expression in UUO mice. As shown in Fig. 2A, we found that the expression of fibronectin in the control and sham groups was not different but was significantly increased in UUO mice and Exo-treated UUO mice. However, the expression of fibronectin in the Exos-H group was decreased compared with that in the UUO group. Furthermore, we analyzed the fibronectin-positive areas of the different groups. As shown in Fig. 2B, The UUO group $(11.35 \% \pm$ 1.79) had the largest area of the 4 groups $(\mathrm{p}<0.05)$, and the area in the Exos-H group $(5.47 \% \pm 0.86)$ was also larger than that of the Con $(1.79 \% \pm 0.19)$ and Sham $(1.99 \% \pm$ $0.28)$ groups $(\mathrm{p}<0.05)$.

\section{PSC-MSC-Exosomes preserved kidney function and inhibited inflammation in UUO mice}

Inflammation plays a crucial role in the development of kidney fibrosis. To confirm the anti-inflammatory effects of PSC-MSC-Exosomes, inflammatory cytokines, including TNF- $\alpha$ and IL-6, were measured by ELISA (Fig. $3 \mathrm{~A})$. The secretion of TNF- $\alpha$ and IL-6 was increased in UUO mice $(p<0.05)$. Conversely, treatment with Exosomes

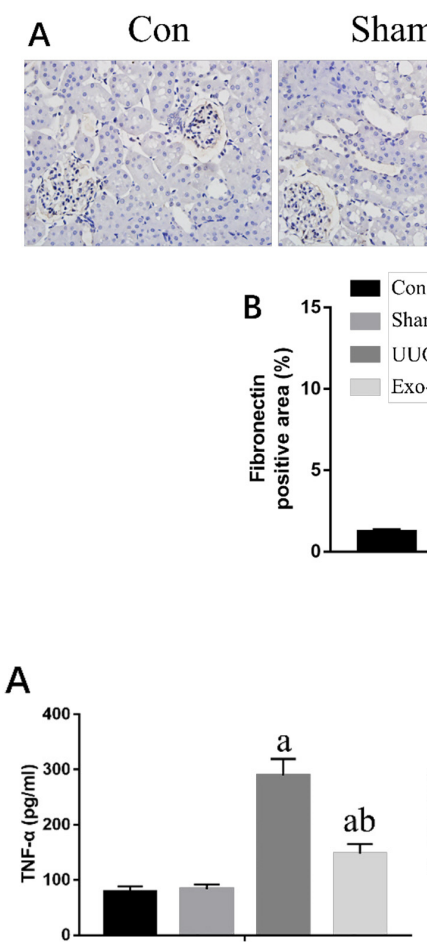

C

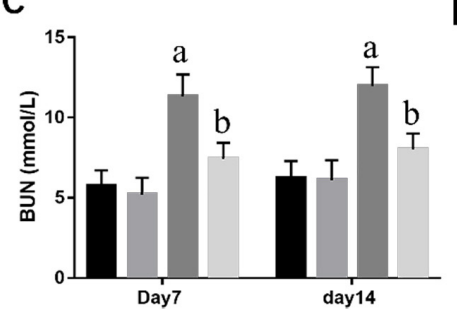

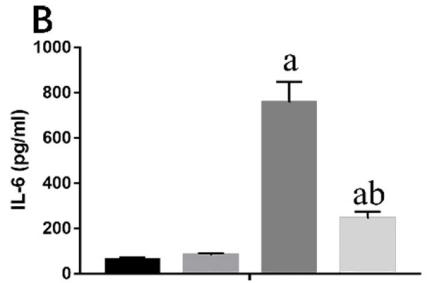

D

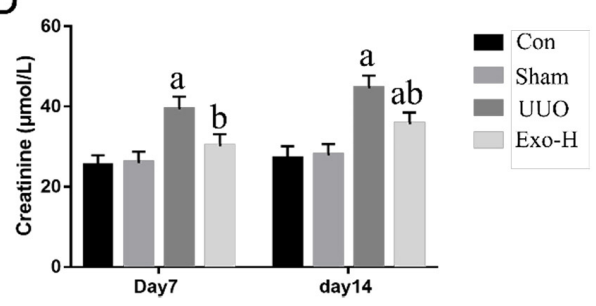

Fig. 2. PSC-MSC-Exosomes inhibited renal fibrosis in UUO mice. (A) Immunohistochemical staining showed that the expression of fibronectin was inhibited by PSC-MSC-Exo administration in UUO-injured mice. (B) Quantitative results of fibronectin expression. Bar $=100 \mu \mathrm{m} . \mathrm{n}=3$ in each group; ${ }^{a} \mathrm{p}<0.05$ vs. the Con group; ${ }^{b} p<0.05$ vs. the UUO group.

Fig. 3. The effect of PSC-MSC-Exosomes on kidney failure and renal inflammation in UUO mice. (A) TNF$\alpha$ levels in the different mice. (B) IL-6 levels in the different mice. (C) BUN levels in the different mice. (D) Serum creatinine levels in the different mice. $\mathrm{n}=6$ in each group; ${ }^{\mathrm{a}} \mathrm{p}<$ 0.05 vs. the Con group; ${ }^{b} p<0.05$ vs. the UUO group. 
attenuated the inflammatory response $(\mathrm{p}<0.05)$.

Kidney function decreases in mice with renal fibrosis, and the levels of serum creatinine and BUN are crucial in helping to evaluate kidney function. Fig. 3C and 3D and Table 2 showed that UUO mice developed serious renal dysfunction compared with normal mice, as indicated by significant increases in serum creatinine and BUN levels. However, the level of BUN was significantly decreased in the Exo-H group at day 7 and day $14(\mathrm{p}<0.05)$ and was similar to the normal level compared with that of the Con and Sham groups $(p>0.05)$. Moreover, the serum creatinine level was also decreased in the Exo-H group compared with the UUO group $(\mathrm{p}<0.05)$, although it was higher than that in the Con group at day $14(\mathrm{p}<$ $0.05)$.

\section{PSC-MSC-Exosomes inhibited renal fibrosis through} the SIRT6/ $\beta$-catenin signaling pathway

To identify the mechanism by which PSC-MSC-Exosomes inhibited renal fibrosis, this study used Western blotting to measure the expression of SIRT6 and $\beta$-catenin in UUO mice. Fig. 4A shows that obstructive injury significantly decreased the expression of SIRT6, whereas Exo treatment reversed these changes in expression levels. While the results in Supplementary Fig. S3 indicated that the synthesis of $\beta$-catenin presented the opposite tendency. We also obtained similar results in vitro (Fig. $4 \mathrm{~B}$ and $4 \mathrm{C}$ ). However, the expression of $\beta$-catenin, a downstream protein of SIRT6, was downregulated in the Exo-H group, while the expression level in the TGF- $\beta 1$ group was between that of the the Con and TGF- $\beta 1$ groups (Fig. 4B). These results indicate that Exosomes can inhibit the expression of $\beta$-catenin by upregulating SIRT6. Subsequently, we used real-time PCR to measure the expression of genes downstream of $\beta$-catenin and found that PAI-1, Fspl and Axin2 were all upregulated in the TGF- $\beta 1$ group $(\mathrm{p}<0.05)$ and significantly decreased in the Exo-H group $(\mathrm{p}<0.05)$.

Table 2. Renal function of mice in the different groups (mean \pm SEM)

\begin{tabular}{llrrrrr}
\hline \multirow{2}{*}{ Group } & $\mathrm{n}$ & \multicolumn{2}{c}{ BUN $(\mathrm{mmol} / \mathrm{l})$} & & \multicolumn{2}{c}{ Creatinine $(\mu \mathrm{mol} / \mathrm{l})$} \\
\cline { 3 - 4 } \cline { 6 - 7 } & & \multicolumn{1}{c}{ Day 7} & Day 14 & & Day 7 & Day 14 \\
\hline Con & 6 & $5.738 \pm 0.972$ & $6.247 \pm 1.047$ & & $25.317 \pm 2.558$ & $27.126 \pm 3.013$ \\
Sham & 6 & $5.213 \pm 1.034$ & $6.132 \pm 1.217$ & & $26.038 \pm 2.731$ & $27.996 \pm 2.698$ \\
UUO & 6 & $11.334 \pm 1.361$ & $11.986 \pm 1.163$ & & $39.442 \pm 3.021$ & $44.568 \pm 3.139$ \\
Exo-H & 6 & $7.439 \pm 0.987$ & $8.035 \pm 0.972$ & & $30.176 \pm 2.967$ & $35.698 \pm 2.847$ \\
\hline
\end{tabular}
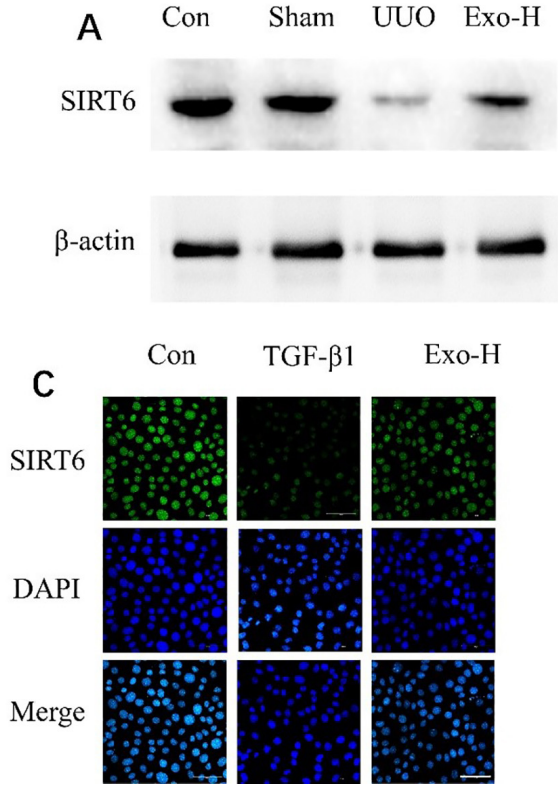

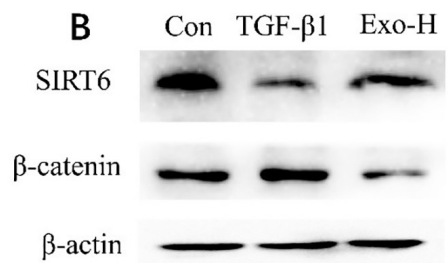

D

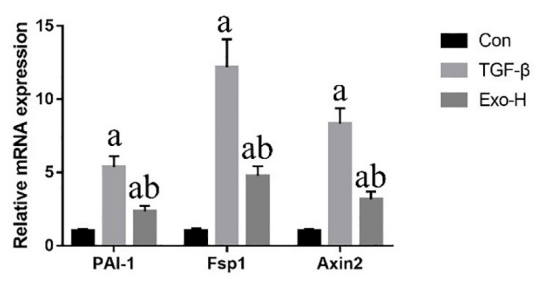

Fig. 4. Mechanism by which exosomes inhibit fibrosis. (A) Western blot analysis of SIRT6 protein expression in the different mice. (B) Western blot analysis of SIRT6 protein expression in NRK-52E cells under different conditions. (C) Representative immunofluorescence images showing SIRT6 in NRK-52E cells under different conditions. (D) PAI-1, Fsp1 and Axin2 gene expression in NRK-52E cells under different conditions. $\mathrm{Bar}=50 \mu \mathrm{m}$. $\mathrm{n}=3$ in each group; ${ }^{\mathrm{a}} \mathrm{p}<0.05$ vs. the Con group; ${ }^{b} \mathrm{p}<0.05$ vs. the TGF- $\beta$ 1 group. 


\section{Discussion}

Currently, there is still a lack of clinically effective therapeutic drugs for renal fibrosis, leading to a large number of renal fibrosis patients inevitably developing end-stage renal disease. The pathological characteristics of renal fibrosis mainly include excessive formation of extracellular matrix, infiltration of inflammatory cells or the production of inflammatory factors, tubular cell dedifferentiation and excessive activation of myofibroblasts. Therefore, the main reason for the difficulty in treating renal fibrosis is that the mechanism of its development is complex, and interacting signaling pathways easily form a compensation mechanism. There is also a lack of effective indicators to evaluate the effect of drugs on renal fibrosis. Most of the currently used drugs have relatively negative side effects, which seriously affect patient compliance. For example, although ACEI (AngiotensinConverting Enzyme Inhibitors) can effectively treat renal fibrosis, long-term prognosis is still poor (22). Therefore, when developing a new therapeutic agent, we must not only ensure the long-term safety of the drug but also ensure the effectiveness of the evaluation plan. It is best to clarify the molecular mechanism of the drug to protect the kidney.

Studies have shown that exosomes have therapeutic potential in various diseases, such as the repair of bone defects (23), nerve regeneration (24) and the treatment of myocardial infarction (25), in the absence of the original cells. Exosomes have been proven to be effective in the treatment of kidney diseases (26). Zhou et al. (27) found that exosomes released by human umbilical cord mesenchymal stem cells (huc-MSCs) protect against cisplatin-induced renal oxidative stress and apoptosis, as well as stimulate kidney cell proliferation by the ERK1/2 signaling pathway. Nagaishi et al. (28) used bMSC (bone marrow stem cells)-derived exosomes to treat diabetic nephropathy and found that pathological kidney tissue damage was improved, proinflammatory factors were decreased, and renal tubular EMT was alleviated. Wang et al. (29) verified that MSCs were able to selectively transfer miR-let7c to damaged kidney cells through exosomes, furthermore paving the way for the use of MSCs to delivery miRNA as a targeted therapy for kidney disease. The underlying mechanism of the positive effects is that exosomes contain growth factors, cytokines, chemokines, proteins, mRNAs, and miRNAs. Therefore, the use of exosomes to treat kidney diseases has good prospects. However, exosomes are a kind of cell-derived nanoparticle, and their functional effects and contents are largely restricted by cell type. The therapeutic effects of MSCs and MSC-Exosomes on kidney disease need not be discussed further. Nevertheless, MSCs will differentiate during the culture process, which affects the function and content of exosomes. Thus, collecting enough exosomes for kidney repair relies on abundant sources of parent cells. Recently, the effectiveness of the application of human-induced pluripotent stem cell-derived mesenchymal stem cells (hiPSC-MSC-Exosomes) in bone defect repair and regeneration has been confirmed. More importantly, hiPSC-MSCs do not differentiate like MSCs but still retain efficacy of MSCs after culturing for 8-9 passages.

TGF- $\beta$ 1-treated NRK-52E cells are often used as an in vitro culture model of renal fibrosis. In this study, we used different concentrations of PSC-MSC-Exosomes to treat TGF- $\beta 1$-treated NRK-52E cells and found that PSCMSC-Exosomes could effectively reverse TGF- $\beta$ 1-treated cell fibrosis in vitro. We believed this effect was exerted via multiple pathways such as the suppression of inflammation caused by the mRNA and proteins contained in exosomes (30). Moreover, higher concentrations led to better effects. Furthermore, the morphology of TGF- $\beta$ 1-treated NRK-52E cells treated with PSC-MSC-Exosomes was closer to the morphology of normal NRK-52E cells. To further confirm the antifibrotic effect of Exosomes in kidneys, we used UUO mice for in vivo experiments. Immunohistochemical staining of kidney sections and ELISA analysis showed that exosomes could partially reverse renal fibrosis and reduce inflammation in the kidney, further improving the kidney function of UUO mice.

SIRT6, a protein that has been reported can protect organs from fibrosis in different ways (31). $\beta$-catenin is considered to be an important link in the process of renal fibrosis (32). Activated $\beta$-catenin can significantly upregulate fibrosis-related proteins, such as fibronectin $(\mathrm{FN})$, matrix metalloproteinase 7 (MMP7), and fibroblast-specific protein 1 (Fsp 1). Recently, Cai et al. (19) found that SIRT6 protects against kidney fibrosis by epigenetically blocking $\beta$-catenin target gene expression. Similarly, in our in vitro experiments, SIRT6 was downregulated and $\beta$-catenin was upregulated in TGF- $\beta 1$-treated NRK-52E cells. Moreover, exosomes derived from PSC-MSCs could increase SIRT6 and reduce $\beta$-catenin in TGF- $\beta 1$-treated NRK-52E cells. In vivo, SIRT6 expression in Exosomestreated UUO mice was lower than that in control mice, but it was significantly higher than that in unexposed UUO mice. Therefore, we concluded that the protective effect of PSC-MSC-Exosomes on renal fibrosis occurred through upregulating SIRT6, thus downregulating the expression of $\beta$-catenin and further reducing the expression 
of downstream products of $\beta$-catenin (Fig. 4, Supplementary Fig. S3).

In summary, this study confirmed that PSC-MSCExosomes have a robust protective effect against renal fibrosis, and higher concentrations of Exos were associated with better protective effects. Moreover, this protection was achieved by regulating the SIRT6/ $\beta$-catenin signaling axis.

In conclusion, PSC-MSC-Exosomes can effectively inhibit endothelial cell injury, reduce inflammatory reaction, protect renal function and slow down renal fibrosis, and this effect is achieved by up regulation of SIRT6, thereby inhibiting the expression of $\beta$-catenin and its downstream products.

\section{Acknowledgments}

This work was supported by The National Natural Science Foundation of Shaanxi Province (2019JQ-036 and 2020SF-117) and The Foundation of Xian Peihua University (PHKT2003).

\section{Potential Conflict of Interest}

The authors have no conflicting financial interest.

\section{Supplementary Materials}

Supplementary data including three figures can be found with this article online at https://doi.org/10.15283/ijsc20184.

\section{References}

1. Wang Y, Xing QQ, Tu JK, Tang WB, Yuan XN, Xie YY, Wang W, Peng ZZ, Huang L, Xu H, Qin J, Xiao XC, Tao LJ, Yuan QJ. Involvement of hydrogen sulfide in the progression of renal fibrosis. Chin Med J (Engl) 2019;132:28722880

2. Bai M, Lei J, Wang S, Ding D, Yu X, Guo Y, Chen S, Du Y, Li D, Zhang Y, Huang S, Jia Z, Zhang A. BMP1 inhibitor UK383,367 attenuates renal fibrosis and inflammation in CKD. Am J Physiol Renal Physiol 2019;317: F1430-F1438

3. Owsiany MT, Hawley CE, Triantafylidis LK, Paik JM. Opioid management in older adults with chronic kidney disease: a review. Am J Med 2019;132:1386-1393

4. Gwon MG, An HJ, Kim JY, Kim WH, Gu H, Kim HJ, Leem J, Jung HJ, Park KK. Anti-fibrotic effects of synthetic TGF- $\beta 1$ and Smad oligodeoxynucleotide on kidney fibrosis in vivo and in vitro through inhibition of both epithelial dedifferentiation and endothelial-mesenchymal transitions. FASEB J 2020;34:333-349

5. Chen YT, Hsu H, Lin CC, Pan SY, Liu SY, Wu CF, Tsai PZ, Liao CT, Cheng HT, Chiang WC, Chen YM, Chu TS,
Lin SL. Inflammatory macrophages switch to CCL17-expressing phenotype and promote peritoneal fibrosis. J Pathol 2020;250:55-66

6. Chow BSM, Kocan M, Shen M, Wang Y, Han L, Chew JY, Wang C, Bosnyak S, Mirabito-Colafella KM, Barsha G, Wigg B, Johnstone EKM, Hossain MA, Pfleger KDG, Denton KM, Widdop RE, Summers RJ, Bathgate RAD, Hewitson TD, Samuel CS. AT1R-AT2R-RXFP1 functional crosstalk in myofibroblasts: impact on the therapeutic targeting of renal and cardiac fibrosis. J Am Soc Nephrol 2019;30:2191-2207

7. Zhao X, Kwan JYY, Yip K, Liu PP, Liu FF. Targeting metabolic dysregulation for fibrosis therapy. Nat Rev Drug Discov 2020;19:57-75

8. Uccelli A, Moretta L, Pistoia V. Mesenchymal stem cells in health and disease. Nat Rev Immunol 2008;8:726-736

9. Zhang S, Hu B, Liu W, Wang P, Lv X, Chen S, Liu H, Shao Z. Articular cartilage regeneration: the role of endogenous mesenchymal stem/progenitor cell recruitment and migration. Semin Arthritis Rheum 2020;50:198-208

10. Harrell CR, Markovic BS, Fellabaum C, Arsenijevic N, Djonov V, Volarevic V. The role of Interleukin 1 receptor antagonist in mesenchymal stem cell-based tissue repair and regeneration. Biofactors 2020;46:263-275

11. Hoogduijn MJ, Lombardo E. Mesenchymal stromal cells anno 2019: dawn of the therapeutic era? Concise review. Stem Cells Transl Med 2019;8:1126-1134

12. Zhao L, Hu C, Zhang P, Jiang H, Chen J. Melatonin preconditioning is an effective strategy for mesenchymal stem cell-based therapy for kidney disease. J Cell Mol Med 2020; 24:25-33

13. Cao J, Wang B, Tang T, Lv L, Ding Z, Li Z, Hu R, Wei Q, Shen A, Fu Y, Liu B. Three-dimensional culture of MSCs produces exosomes with improved yield and enhanced therapeutic efficacy for cisplatin-induced acute kidney injury. Stem Cell Res Ther 2020;11:206

14. Peng KY, Lee YW, Hsu PJ, Wang HH, Wang Y, Liou JY, Hsu SH, Wu KK, Yen BL. Human pluripotent stem cell (PSC)-derived mesenchymal stem cells (MSCs) show potent neurogenic capacity which is enhanced with cytoskeletal rearrangement. Oncotarget 2016;7:43949-43959

15. Zhang J, Liu X, Li H, Chen C, Hu B, Niu X, Li Q, Zhao B, Xie Z, Wang Y. Exosomes/tricalcium phosphate combination scaffolds can enhance bone regeneration by activating the PI3K/Akt signaling pathway. Stem Cell Res Ther 2016;7:136

16. Sfougataki I, Varela I, Stefanaki K, Karagiannidou A, Roubelakis MG, Kalodimou V, Papathanasiou I, TraegerSynodinos J, Kitsiou-Tzeli S, Kanavakis E, Kitra V, Tsezou A, Tzetis M, Goussetis E. Proliferative and chondrogenic potential of mesenchymal stromal cells from pluripotent and bone marrow cells. Histol Histopathol 2020;35:14151426

17. Muraoka H, Hasegawa K, Sakamaki Y, Minakuchi H, Kawaguchi T, Yasuda I, Kanda T, Tokuyama H, Wakino $\mathrm{S}$, Itoh H. Role of Nampt-Sirt6 axis in renal proximal tu- 
bules in extracellular matrix deposition in diabetic nephropathy. Cell Rep 2019;27:199-212.e5

18. Liu M, Liang K, Zhen J, Zhou M, Wang X, Wang Z, Wei X, Zhang Y, Sun Y, Zhou Z, Su H, Zhang C, Li N, Gao C, Peng J, Yi F. Sirt6 deficiency exacerbates podocyte injury and proteinuria through targeting Notch signaling. Nat Commun 2017;8:413

19. Cai J, Liu Z, Huang X, Shu S, Hu X, Zheng M, Tang C, Liu Y, Chen G, Sun L, Liu H, Liu F, Cheng J, Dong Z. The deacetylase sirtuin 6 protects against kidney fibrosis by epigenetically blocking $\beta$-catenin target gene expression. Kidney Int 2020;97:106-118

20. Kalluri R, LeBleu VS. The biology, function, and biomedical applications of exosomes. Science 2020;367:eaau6977

21. Théry C, Witwer KW, Aikawa E, Alcaraz MJ, Anderson JD, Andriantsitohaina R, Antoniou A, Arab T, Archer F, Atkin-Smith GK, Ayre DC, Bach JM, Bachurski D, Baharvand H, Balaj L, Baldacchino S, Bauer NN, Baxter AA, Bebawy M, Beckham C, Bedina Zavec A, Benmoussa A, Berardi AC, Bergese P, Bielska E, Blenkiron C, Bobis-Wozowicz S, Boilard E, Boireau W, Bongiovanni A, Borràs FE, Bosch $\mathrm{S}$, Boulanger $\mathrm{CM}$, Breakefield X, Breglio AM, Brennan MÁ, Brigstock DR, Brisson A, Broekman ML, Bromberg JF, Bryl-Górecka P, Buch S, Buck AH, Burger D, Busatto S, Buschmann D, Bussolati B, Buzás EI, Byrd JB, Camussi G, Carter DR, Caruso S, Chamley LW, Chang YT, Chen C, Chen S, Cheng L, Chin AR, Clayton A, Clerici SP, Cocks A, Cocucci E, Coffey RJ, Cordeiroda-Silva A, Couch Y, Coumans FA, Coyle B, Crescitelli R, Criado MF, D'Souza-Schorey C, Das S, Datta Chaudhuri A, de Candia P, De Santana EF, De Wever O, Del Portillo HA, Demaret T, Deville S, Devitt A, Dhondt B, Di Vizio D, Dieterich LC, Dolo V, Dominguez Rubio AP, Dominici M, Dourado MR, Driedonks TA, Duarte FV, Duncan HM, Eichenberger RM, Ekström K, El Andaloussi S, Elie-Caille C, Erdbrügger U, Falcón-Pérez JM, Fatima F, Fish JE, Flores-Bellver M, Försönits A, Frelet-Barrand A, Fricke F, Fuhrmann G, Gabrielsson S, Gámez-Valero A, Gardiner C, Gärtner K, Gaudin R, Gho YS, Giebel B, Gilbert C, Gimona M, Giusti I, Goberdhan DC, Görgens A, Gorski SM, Greening DW, Gross JC, Gualerzi A, Gupta GN, Gustafson D, Handberg A, Haraszti RA, Harrison P, Hegyesi H, Hendrix A, Hill AF, Hochberg FH, Hoffmann KF, Holder B, Holthofer H, Hosseinkhani B, Hu G, Huang Y, Huber V, Hunt S, Ibrahim AG, Ikezu T, Inal JM, Isin $M$, Ivanova A, Jackson HK, Jacobsen S, Jay SM, Jayachandran M, Jenster G, Jiang L, Johnson SM, Jones JC, Jong A, Jovanovic-Talisman T, Jung S, Kalluri R, Kano SI, Kaur S, Kawamura Y, Keller ET, Khamari D, Khomyakova E, Khvorova A, Kierulf P, Kim KP, Kislinger T, Klingeborn M, Klinke DJ 2nd, Kornek M, Kosanović MM, Kovács ÁF, Krämer-Albers EM, Krasemann S, Krause M, Kurochkin IV, Kusuma GD, Kuypers S, Laitinen S, Langevin SM, Languino LR, Lannigan J, Lässer C, Laurent LC, Lavieu G, Lázaro-Ibáñez E, Le Lay S, Lee MS, Lee YXF, Lemos DS, Lenassi M, Leszczynska A, Li
IT, Liao K, Libregts SF, Ligeti E, Lim R, Lim SK, Linē A, Linnemannstöns $\mathrm{K}$, Llorente A, Lombard CA, Lorenowicz MJ, Lörincz ÁM, Lötvall J, Lovett J, Lowry MC, Loyer X, Lu Q, Lukomska B, Lunavat TR, Maas SL, Malhi H, Marcilla A, Mariani J, Mariscal J, MartensUzunova ES, Martin-Jaular L, Martinez MC, Martins VR, Mathieu M, Mathivanan S, Maugeri M, McGinnis LK, McVey MJ, Meckes DG Jr, Meehan KL, Mertens I, Minciacchi VR, Möller A, Møller Jørgensen M, MoralesKastresana A, Morhayim J, Mullier F, Muraca M, Musante L, Mussack V, Muth DC, Myburgh KH, Najrana T, Nawaz M, Nazarenko I, Nejsum P, Neri C, Neri T, Nieuwland R, Nimrichter L, Nolan JP, Nolte-'t Hoen EN, Noren Hooten N, O'Driscoll L, O'Grady T, O'Loghlen A, Ochiya T, Olivier M, Ortiz A, Ortiz LA, Osteikoetxea X, Østergaard O, Ostrowski M, Park J, Pegtel DM, Peinado H, Perut F, Pfaffl MW, Phinney DG, Pieters BC, Pink RC, Pisetsky DS, Pogge von Strandmann E, Polakovicova I, Poon IK, Powell BH, Prada I, Pulliam L, Quesenberry P, Radeghieri A, Raffai RL, Raimondo S, Rak J, Ramirez MI, Raposo G, Rayyan MS, Regev-Rudzki N, Ricklefs FL, Robbins PD, Roberts DD, Rodrigues SC, Rohde E, Rome S, Rouschop KM, Rughetti A, Russell AE, Saá P, Sahoo S, SalasHuenuleo E, Sánchez C, Saugstad JA, Saul MJ, Schiffelers RM, Schneider R, Schøyen TH, Scott A, Shahaj E, Sharma S, Shatnyeva O, Shekari F, Shelke GV, Shetty AK, Shiba K, Siljander PR, Silva AM, Skowronek A, Snyder OL 2nd, Soares RP, Sódar BW, Soekmadji C, Sotillo J, Stahl PD, Stoorvogel W, Stott SL, Strasser EF, Swift S, Tahara H, Tewari M, Timms K, Tiwari S, Tixeira R, Tkach M, Toh WS, Tomasini R, Torrecilhas AC, Tosar JP, Toxavidis V, Urbanelli L, Vader P, van Balkom BW, van der Grein SG, Van Deun J, van Herwijnen MJ, Van Keuren-Jensen K, van Niel G, van Royen ME, van Wijnen AJ, Vasconcelos MH, Vechetti IJ Jr, Veit TD, Vella LJ, Velot É, Verweij FJ, Vestad B, Viñas JL, Visnovitz T, Vukman KV, Wahlgren J, Watson DC, Wauben MH, Weaver A, Webber JP, Weber V, Wehman AM, Weiss DJ, Welsh JA, Wendt S, Wheelock AM, Wiener Z, Witte L, Wolfram J, Xagorari A, Xander P, Xu J, Yan X, Yáñez-Mó M, Yin H, Yuana Y, Zappulli V, Zarubova J, Žèkas V, Zhang JY, Zhao Z, Zheng L, Zheutlin AR, Zickler AM, Zimmermann P, Zivkovic AM, Zocco D, Zuba-Surma EK. Minimal information for studies of extracellular vesicles 2018 (MISEV2018): a position statement of the International Society for Extracellular Vesicles and update of the MISEV2014 guidelines. J Extracell Vesicles 2018;7:1535750

22. Sun N, Zhai L, Li H, Shi LH, Yao Z, Zhang B. Angiotensin-converting enzyme inhibitor (ACEI)-mediated amelioration in renal fibrosis involves suppression of mast cell degranulation. Kidney Blood Press Res 2016;41:108-118

23. Tan SHS, Wong JRY, Sim SJY, Tjio CKE, Wong KL, Chew JRJ, Hui JHP, Toh WS. Mesenchymal stem cell exosomes in bone regenerative strategies- a systematic review of preclinical studies. Mater Today Bio 2020;7:100067

24. Chen J, Ren S, Duscher D, Kang Y, Liu Y, Wang C, Yuan 
M, Guo G, Xiong H, Zhan P, Wang Y, Machens HG, Chen $Z$. Exosomes from human adipose-derived stem cells promote sciatic nerve regeneration via optimizing Schwann cell function. J Cell Physiol 2019;234:23097-23110

25. Mao Q, Liang XL, Zhang CL, Pang YH, Lu YX. LncRNA KLF3-AS1 in human mesenchymal stem cell-derived exosomes ameliorates pyroptosis of cardiomyocytes and myocardial infarction through $\mathrm{miR}-138-5 \mathrm{p} /$ Sirtl axis. Stem Cell Res Ther 2019;10:393

26. Thongboonkerd V. Roles for exosome in various kidney diseases and disorders. Front Pharmacol 2020;10:1655

27. Zhou Y, Xu H, Xu W, Wang B, Wu H, Tao Y, Zhang B, Wang M, Mao F, Yan Y, Gao S, Gu H, Zhu W, Qian H. Exosomes released by human umbilical cord mesenchymal stem cells protect against cisplatin-induced renal oxidative stress and apoptosis in vivo and in vitro. Stem Cell Res Ther 2013;4:34

28. Nagaishi K, Mizue Y, Chikenji T, Otani M, Nakano M, Konari N, Fujimiya M. Mesenchymal stem cell therapy ameliorates diabetic nephropathy via the paracrine effect of renal trophic factors including exosomes. Sci Rep 2016;6:

\section{2}

29. Wang B, Yao K, Huuskes BM, Shen HH, Zhuang J, Godson C, Brennan EP, Wilkinson-Berka JL, Wise AF, Ricardo SD. Mesenchymal stem cells deliver exogenous micrornalet7c via exosomes to attenuate renal fibrosis. Mol Ther 2016;24:1290-1301

30. Mansouri N, Willis GR, Fernandez-Gonzalez A, Reis M, Nassiri S, Mitsialis SA, Kourembanas S. Mesenchymal stromal cell exosomes prevent and revert experimental pulmonary fibrosis through modulation of monocyte phenotypes. JCI Insight 2019;4:e128060

31. Hao L, Bang IH, Wang J, Mao Y, Yang JD, Na SY, Seo JK, Choi HS, Bae EJ, Park BH. ERR $\gamma$ suppression by Sirt6 alleviates cholestatic liver injury and fibrosis. JCI Insight 2020;5:e137566

32. Rao P, Pang M, Qiao X, Yu H, Wang H, Yang Y, Ren X, Hu M, Chen T, Cao Q, Wang Y, Khushi M, Zhang G, Wang YM, Heok P'ng C, Nankivell B, Lee VW, Alexander SI, Zheng G, Harris DC. Promotion of $\beta$-catenin/Foxol signaling ameliorates renal interstitial fibrosis. Lab Invest 2019;99:1689-1701 